\title{
Analisa Numerik Pegaruh Karakteristik Gelombang Air Laut pada Wave Energy Converter Tipe Bottom Hinge Menggunakan Metode Smoothed Particles Hydrodynamics
}

\author{
Avicenna An-Nizhami ${ }^{1 *}$, Elfrida Rizky Riadini ${ }^{2}$ \\ ${ }^{1}$ Jurusan Teknik Mesin, Politeknik Negeri Semarang, \\ Tembalang 50275, Semarang, Jawa Tengah, Indonesia, \\ 2 Departemen Teknik Mesin dan Industri, Fakultas Teknik, Universitas Gadjah Mada, \\ Depok 55281, Sleman, Daerah Istimewa Yogyakarta \\ *E-mail: avicenna@polines.ac.id
}

Diterima: 25-02-2021; Direvisi: 26-03-2021; Dipublikasi: 27-04-2021

\begin{abstract}
Abstrak
Energi terbarukan yang bersumber dari gelombang air laut menjadi dasar penelitian ini. Penelitian ini bertujuan untuk menganalisa Wave Energy Converter (WEC) tipe bottom hinge menggunakan metode numerik Smoothed Particle Hydrodynamics (SPH). Dinamika gerak dari WEC didekati dengan persaman getaran torsional dengan memodelkan generator sebagai spring dan damper. Pada metode SPH domain penelitian didiskritkan menjadi partikel yang merepresentasikan partikel fluida dan partikel solid. Persamaan atur yang digunakan adalah konservasi massa dan momentum. Validasi menunjukkan bahwa metode SPH dapat dengan akurat meprediksi dinamika gelombang air laut. Gaya hidrodinamis dan energi yang dihasilkan oleh WEC mempunyai nilai yang fluktuatif namun dengan pola yang periodik.
\end{abstract}

Kata kunci: free surface; gelombang air laut; getaran torsional; SPH; wave energy

\begin{abstract}
Renewable energy extracted from the ocean waves is the basis of this study. The aim of this study is to analyze bottom hinge type Wave Energy Converter (WEC) using numerical method Smoothed Particles Hydrodynamics (SPH). The dynamics of WEC is approximated by torsional vibration equation by modeling the generator as spring and damper system.The SPH method, the fluid and solid domain is dicretized as fluid and solid particles. Governing equation implemented in the SPH is conservasion of mass and momentum. The results of validation indicates that the SPH method capable to accurately predict the dynamics of the ocean waves. The Hydrodynamics force and extracted energy from WES produced transient results with periodic pattern.
\end{abstract}

Keywords: free surface; ocean way; torsional vibration; SPH; wave energy

\section{Pendahuluan}

Pemanfaatan energi terbarukan sebagai subtitusi energi yang bersumber dari fosil dapat berupa energi yang bersumber dari angin, panas bumi, cahaya matahari maupun gelombang air laut. Luasnya lautan di Indonesia menjadi potensi dalam mengembangkan pembangkit listrik tenaga gelombang air laut [1]. Selain itu ketersediaan energi pada gelombang air laut lebih konstan, andal [2] dan lebih bervariasi dibandingkan pembangkit listrik tenaga angin [3]. Pengembangan teknologi Wave Energy Converter (WEC) banyak dilakukan agar gelombang air laut dapat dimanfaatkan untuk membangkitkan listrik. Pada dasarnya, prinsip kerja WEC adalah memanfaatkan karakteristik gelombang air laut yang memiliki karakter berosilasi dimana partikel fluida dibawah gelombang memiliki lintasan orbit berbentuk lingkaran ataupun oval tergantung dari karakteristik gelombang [4]. Secara umum WEC dapat dikategorikan menjadi Oscillating Water Coloumb (OWC), point absorber, overtopping dan bottom hinge [5].

Kasus-kasus WEC telah banyak dikaji pada penelitian-penelitian terdahulu, dan metode numerik terbukti dapat dengan akurat memprediksi dinamika fluida dan gerak pada WEC [5,6]. Namun pada implementasinya terdapat batasan-batasan dalam mensimulasikan kasus terkait WEC, antara lain ketidakmampuan beberapa metode numerik 
untuk mensimulasikan adanya wave breaking yang pada kenyataannya pasti akan terjadi. Jadi, tantangan dalam mensimulasikan WEC adalah adanya kondisi batas free surface yang kompleks dan terus berevolusi. Oleh karena itu diimplementasikan metode Smoothed Particle Hydrodynamics (SPH) pada kasus WEC. Metode SPH adalah metode lagrangian tanpa mesh dimana domain fluida direpresentasikan oleh partikel diskit yang setiap partikel memiliki sifatsifat dari fluida seperti posisi, kecepatan tekanan dan massa [7]. Sifat adaptif dari metode SPH akan memudahkan dalam menerapkan kondisi batas free surface dikarenakan prediksi partikel tidak dipengaruhi oleh keacakan posisi partikel.

Penelitian tentang WEC tipe bottom hinge sampai sekarang masih terbatas, khususnya pendekatan generator yang diimplementasikan sebagai model spring dan damper masih belum dikaji. Pada penelitian kali ini akan dilakukan penelitian terhadap potensi energi yang dihasilkan, dinamika fluida dan dinamika gerak dari WEC tipe bottom hinge. Terdapat dua tahapan pada penelitian ini. Tahap pertama adalah validasi, kasus yang akan divalidasi adalah wave induced motion of freely floating body dan akan dibandingkan dengan hasil eksperimen oleh Ren dkk. [8]. Tahap kedua adalah kajian pada kasus WEC tipe bottom hinge dengan parameter periode dan tinggi gelombang air laut.

\section{Material dan metodologi}

Penelitian akan dilakukan menggunakan metode SPH dengan open source DualSPHysics yang dikembangkan oleh Crespo dkk. [9] yang ditulis dengan Bahasa C++ dan CUDA. DualSPHysics berbasiskan kode dari open source SPHysics [10,11] dengan Bahasa Fortran fixed format.

\subsection{Persamaan atur}

Persamaan atur yang diimplementasikan pada DualSPHysics meliputi persamaan kontinuitas dan persamaan konservasi momentum. Persamaan kontinuitas pada metode SPH didekati dengan model weakly compressible [12], dimana massa jenis fluida berubah terhadap waktu. Sehingga nilai tekanan dihitung dari massa jenis menggunakan persamaan Tait [13]. Persamaan kontinuitas dalam bentuk continuиm dapat dilihat pada Pers. (1), dimana $\boldsymbol{\rho}$ dan $\mathbf{u}$ adalah massa jenis dan kecepatan fluida. Persamaan konservasi momentum yang digunakan adalah persamaan Navier Stoke tertulis pada Pers. (2), dimana $\boldsymbol{p}, \boldsymbol{v}$ dan $\mathbf{g}$ masing-masing adalah tekanan, viskositas kinematik dan percepatan gravitasi. Bentuk continuum dari Pers. (1) didiskritkan menggunakan metode SPH menjadi Pers. (3).

$$
\begin{aligned}
\frac{D \rho}{D t} & =-\rho \cdot \nabla \cdot \mathbf{u} \\
\frac{D \mathbf{u}}{D t} & =-\frac{\nabla p}{\rho}+\nu \nabla^{2} \mathbf{u}+\mathbf{g} \\
\frac{D \rho_{i}}{D t} & =\sum_{b} m_{i} \mathbf{u}_{i j} \cdot \nabla_{i} W_{i j}+\delta_{\phi} h c_{0} \sum_{b} \psi_{i j} \cdot \nabla_{i} W_{i j} \frac{m_{j}}{\rho_{j}}
\end{aligned}
$$

Dengan $\boldsymbol{\Psi}_{i j}=\mathbf{2}\left(\boldsymbol{\rho}_{j}-\boldsymbol{\rho}_{i}\right) \frac{\mathbf{x}_{i j}}{\left\|\mathbf{x}_{i j}\right\|^{\|^{*}}}$. Persamaan (3) ruas kanan suku pertama adalah bentuk diskrit dari divergence kecepatan sedangkan pada suku kedua merupakan term tambahan untuk memfilter kontur tekanan dengan cara memfilter kontur massa jenis yang dinamakan Density Diffusive Term (DDT). DDT dikembangkan oleh Molteni dkk. [14] dan dikembangkan lebih lanjut lagi oleh Fourtakas dkk. [15]. Pers. (2) didiskritkan menggunakan metode SPH sebagai Pers. (4). Hasil perhitungan dari Pers. (4) dan (5) diintegrasi terhadap waktu menggunakan metode symplectic [16]. 


$$
\frac{D \mathbf{u}}{D t}=-\sum_{b} \frac{p_{i}+p_{j}}{\rho_{i} \rho_{j}} \cdot \nabla_{i} W_{i j}+\sum_{b} m_{j}\left(\frac{4 v \mathbf{r}_{i j} \cdot \nabla_{i} W_{i j}}{\left(\rho_{i}+\rho_{j}\right)\left(\mathbf{r}_{i j}+\eta\right)}\right)+\mathbf{g}
$$

\section{Hasil dan pembahasan}

\subsection{Validasi kasus floating body}

Skema kasus validasi ditujukkan pada Gambar 1. Parameter yang digunakan disamakan dengan parameter ekperimen oleh Ren dkk. [8]. Karakteristik gelombang pada kasus validasi antara lain, pariode gelombang, $T=1.2 \mathrm{~s}$, tinggi gelombang $H=0.1 \mathrm{~m}$ dan kedalaman $d=0.4 \mathrm{~m}$. Ukuran floating body adalah $0.2 \times 0.3 \mathrm{~m}$. Kondisi batas yang diimplementasikan pada kasus ini dapat dilihat pada Gambar 1.

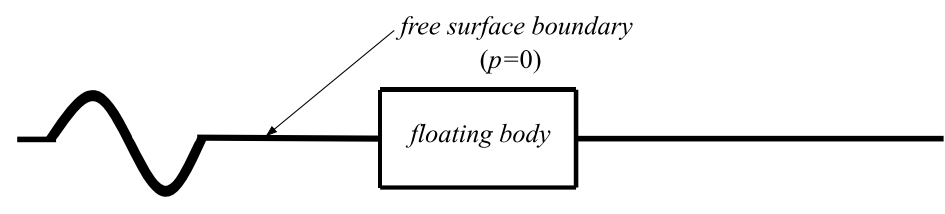

Kondisi batas no slip, $(u, v)=0$

Gambar 1. Skema domain kasus validasi

Kondisi batas free surface merepresentasikan permukaan fluida dengan tekanan gauge 0 [Pa]. Kondisi batas pada wall bagian bawah dan kanan adalah kondisi batas no slip dimana kecepatan arah sumbu $\mathrm{x}$ dan y bernilai 0 [m/s]. Kondisi batas pada wall sebelah kanan adalah wave maker dengan gerakan disesuaikan dengan eksperimen Ren dkk. [8]. Dinamika gerak floating body menggunakan persamaan gaya dari Hukum Newton ke 2 ditunjukkan pada Persamaan (5). Parameter yang akan divalidasi adalah surge dan heave dari floating body. Surge dan heave masingmasing adalah gerakan floating body arah sumbu x dan y dalam domain waktu. Hasil dari simulasi yang dibandingkan dengan data eksperimen Ren dkk. [8] pada kasus floating body dapat dilihat pada Gambar 2.

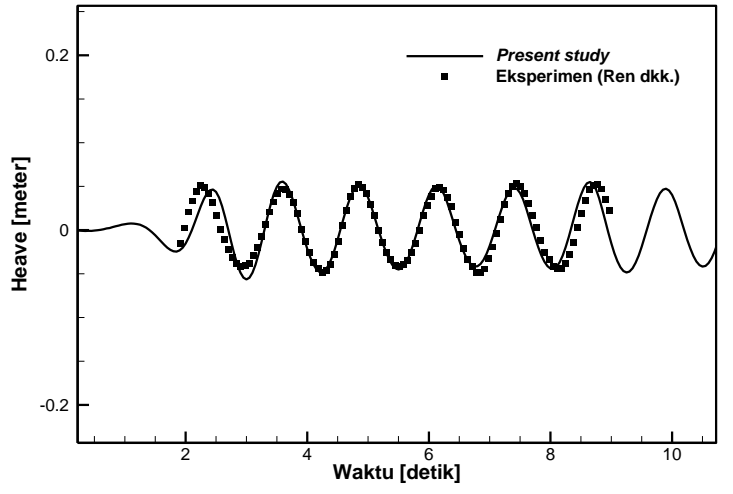

(a)

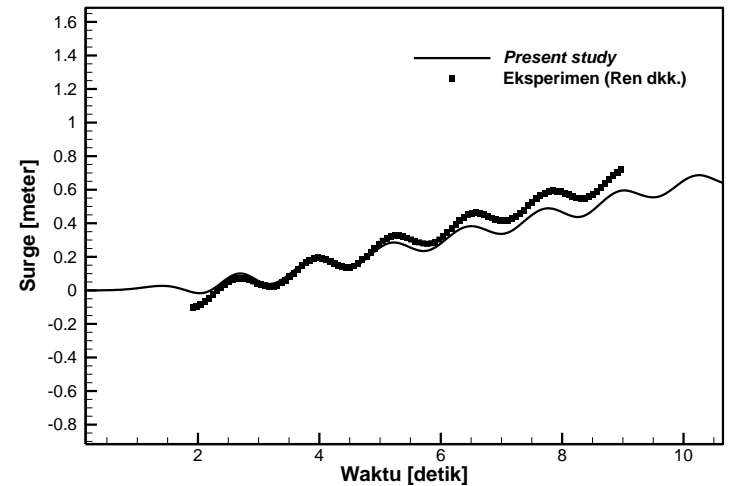

(b)

Gambar 2. Perbandingan kasus floating body dengan hasil eksperimen Ren dkk. [17]

(a). Heave dan (b). Surge, pada domain waktu 
Hasil simulasi yang berupa data heave dan surge dari floating body memiliki hasil yang mendekati data eksperimen Ren dkk. [8]. Persentase error yang dihasilkan oleh hasil simulasi dihitung dengan membandingkan root mean square (RMS) hasil simulasi dengan eksperimen. Persentase error RMS sebesar $1.36 \%$ untuk heave dan $2.01 \%$ untuk surge, sehingga dapat disimpulkan data yang dihasilkan adalah akurat dan dapat dilanjutkan dengan analisa WEC.

$$
M \frac{d V}{d t}=\sum_{k \in B P S} F_{k}
$$

\subsection{Analisa hasil WEC}

Skema domain kasus yang akan dikaji ditunjukkan pada Gambar 2. Parameter karakteristik gelombang yang digunakan adalah periode, $T$, dengan nilai $2 \mathrm{~s}$ dan ketinggian gelombang, $H, 0.5 \mathrm{~m}$. kondisi batas yang diimplementasikan sama dengan kasus validasi, kecuali pada persamaan gerak flap menggunakan persamaan getaran torsional seperti pada Pers. (6). Pada sumbu rotasi flap dihubungkan oleh generator yang direpresentasikan dengan torsional spring dan damper. Hasil yang didapatkan adalah visualisasi dari simulasi, grafik gaya, dan potensi energi yang bisa dimanfaatkan.

$$
I \frac{d^{2} \boldsymbol{\theta}}{d t^{2}}=\sum_{k \in B P S} F_{k}\left(r_{k}-R_{0}\right)-(k \times d \boldsymbol{\theta})-\left(c \times \frac{d \boldsymbol{\theta}}{d t}\right)
$$
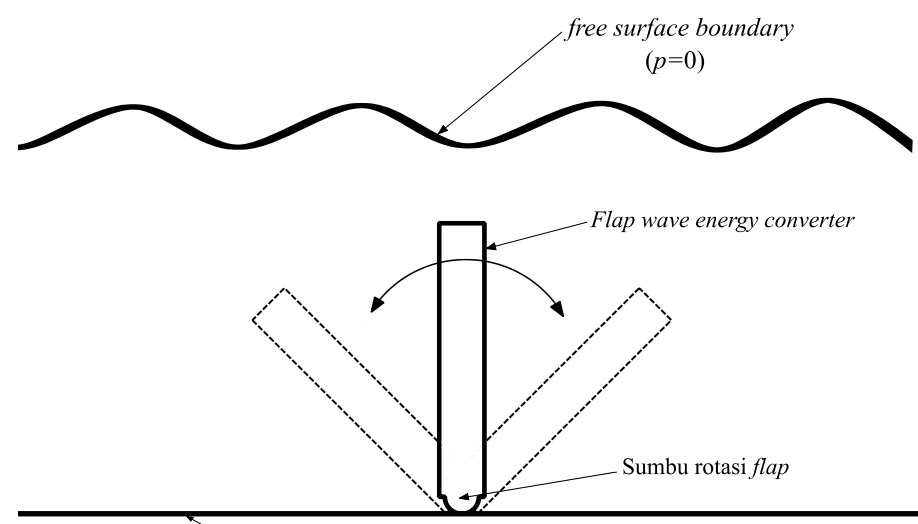

Kondisi batas no slip, $(u, v)=0$

Gambar 3. Skema domain OWC tipe bottom hinge menggunakan flap

Kontur vorticity yang mereprensentasikan proses pembentukan vortex pada empat waktu yang berbeda ditunjukkan pada Gambar 5. Pembentukan vortex positif terjadi saat WEC bergerak berlawanan arah jarum jam. Sebaliknya, vortex negatif terbentuk saat WEC bergerak searah jarum jam. Sebelum terjadinya fenomena vortex shedding yang yang ditunjukan pada Gambar 5c mengakibatkan adanya fluktuasi tekanan [18] akibat dari tekanan pada pusat vortex yang rendah. Hal itu mengakibatkan munculnya spike/ puncak kedua pada gaya hidrodinamis yang ditunjukkan pada Gambar 6. Adanya spike pada gaya hidrodinamis tidak berpengaruh signifikan terhadap dinamika gerak dan energi yang dihasilkan oleh WEC. Gaya hidrodinamis yang dihasilkan menunjukkan pola yang periodik namun dengan sedikit fluktuasi pada nilai amplitudonya. Potensi energi yang dapat dimanfaatkan dapat direprenstasikan sebagai energi kinetik yang dihasilkan oleh WEC. Grafik energi yang dihasilkan pada domain waktu dapat dilihat pada 
Avicenna An-Nizhami dkk /Jurnal Rekayasa Mesin p-ISSN: 1411-6863, e-ISSN: 2540-7678

Vol.16|No.1|32-38|April|2021

Gambar 7. Energi yang dihasilkan mempunyai sifat periodik yang mempunyai dua puncak dengan nilai yang berbeda. Perbedaan nilai puncak diakibatkan oleh gerakan dari WEC, saat WEC bergerak searah dengan gerakan gelombang menghasilkan nilai puncak yang lebih besar dibandingkan saat WEC bergerak berlawanan dengan arah gelombang. Dari hasil simulasi didapatkan total potensi energi yang dapat dimanfaatkan selama kurun waktu 60 [detik] adalah $16.34[\mathrm{~kJ}]$.

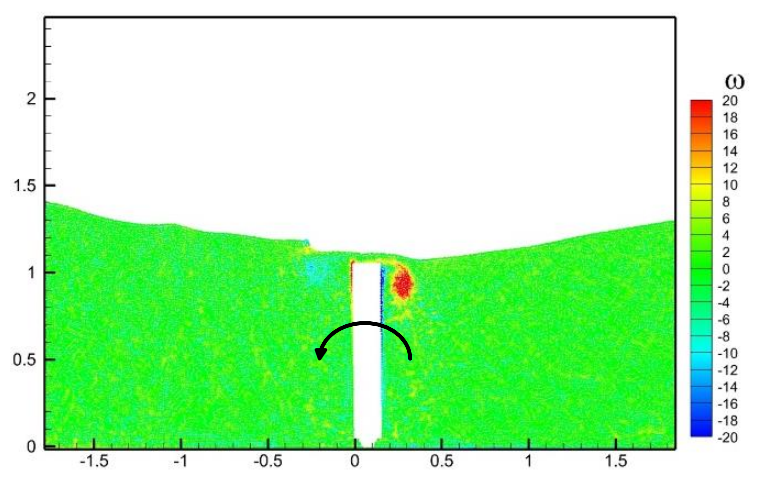

(a)

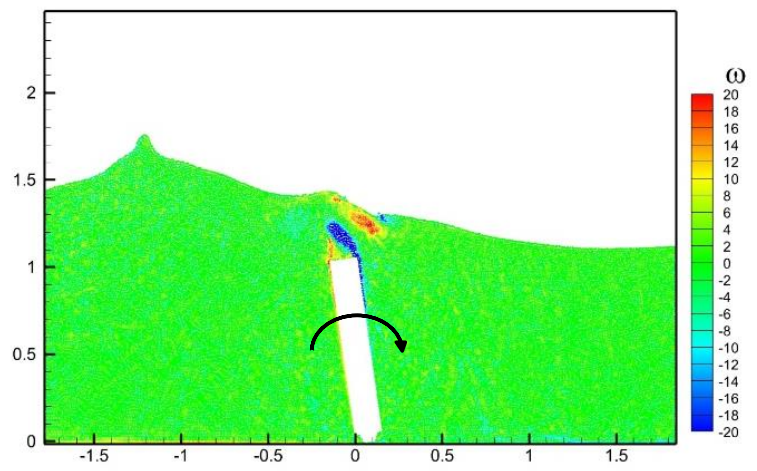

(c)

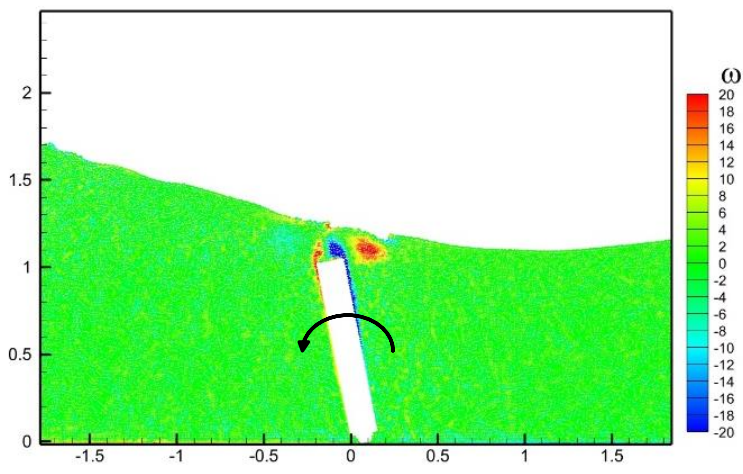

(b)

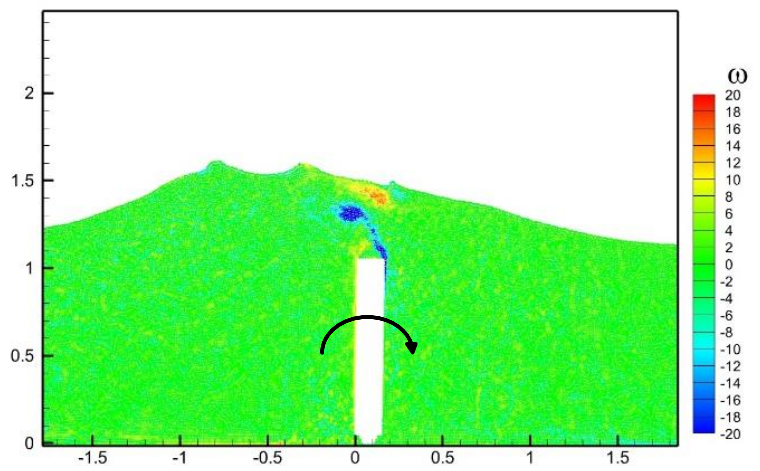

(d)

Gambar 4. Kontur vorticity pada: (a). $\mathrm{t}=16.86$ [detik], (b). $\mathrm{t}=17.2$ [detik], (c). $\mathrm{t}=17.4$ [detik] dan (d). $\mathrm{t}=17.64$ [detik]

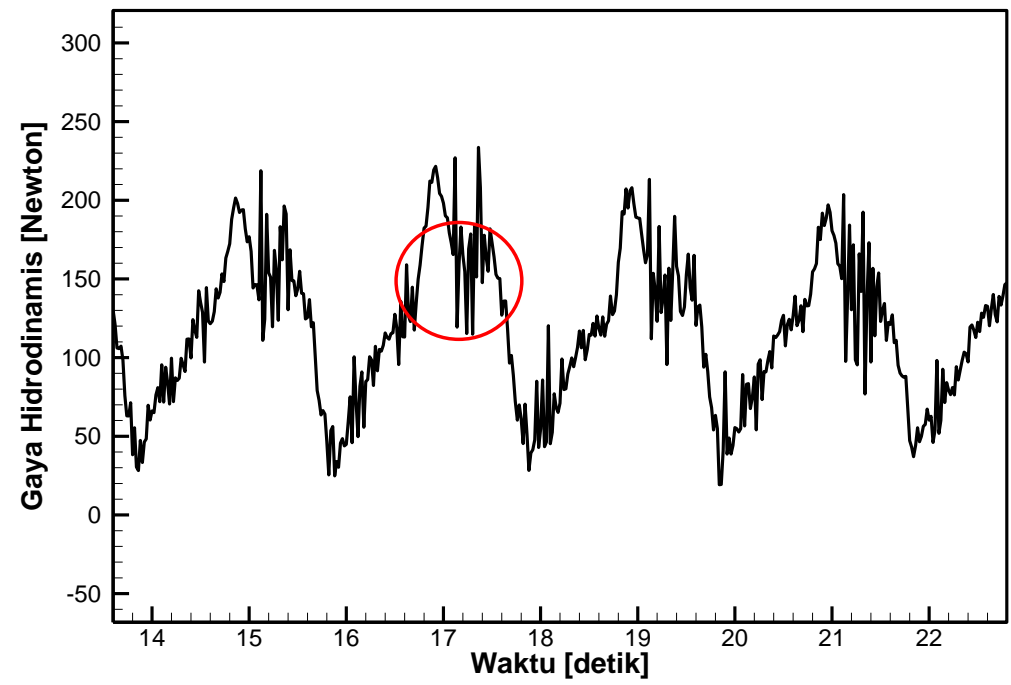

Gambar 5. Gaya hidrodinamis yang diterima oleh WEC pada domain waktu 


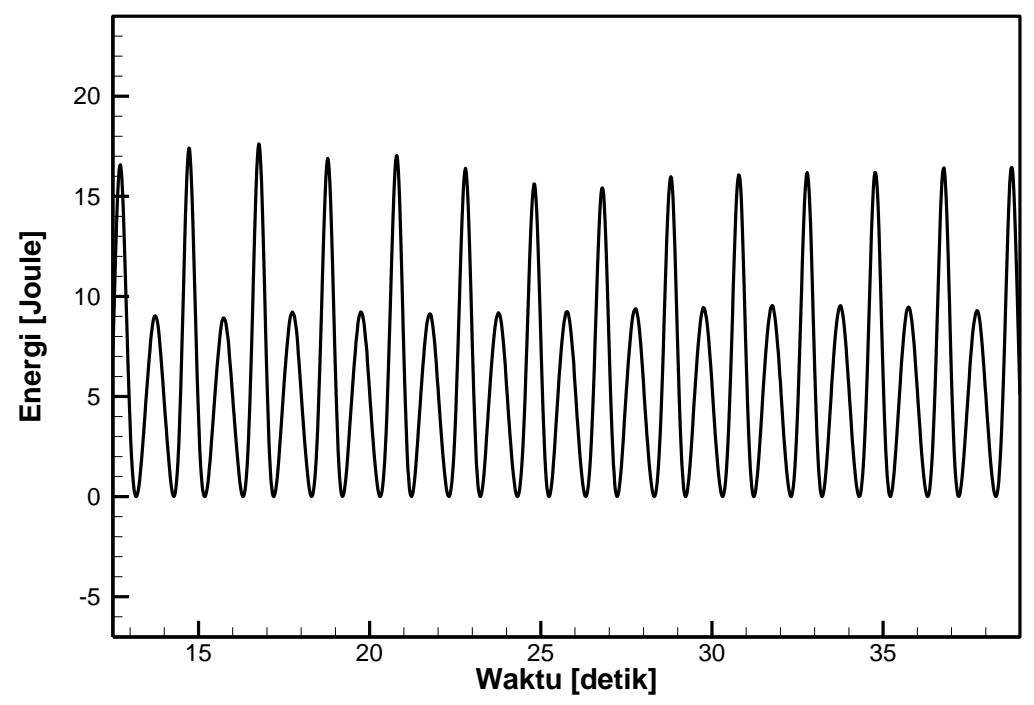

Gambar 6. Energi kinetik yang dihasilkan oleh WEC dalam domain waktu

\section{Kesimpulan}

Simulasi dan Analisa WEC tipe bottom hinge telah dilakukan menggunakan metode Smoothed Particles Hydrodynamics dengan memodelkan generator sebagai spring dan damper. Validasi dilakukan dengan membandingkan hasil dengan penelitian sebelumnya. Hasil validasi menunjukkan bahwa simulasi fluida dengan kondisi batas free surface memiliki persentase error $1.36 \%$ dan 2.01\%. Dari analisa WEC, gaya hidrodinamis dan energi yang dihasilkan mempunyai pola yang periodik dengan sedikit variasi pada amplitudonya. Pada gaya hidrodinamis muncul spike akibat adanya vortex shedding.

\section{Daftar Pustaka}

[1] Kementrian Energi dan Sumber Daya Mineral, "RENSTRA (RENCANA STRATEGIS) DITJEN EBTKE 20152019". 2015.

[2] J. Falnes, "A review of wave-energy extraction," Mar. Struct., vol. 20, no. 4, pp. 185-201, 2007, doi: 10.1016/j.marstruc.2007.09.001.

[3] A. F. D. O. Falcão, "Wave energy utilization: A review of the technologies," Renew. Sustain. Energy Rev., vol. 14, no. 3, pp. 899-918, 2010, doi: 10.1016/j.rser.2009.11.003.

[4] R. G. Dean, R. A. Dalrymple, WATER WAVE MECHANICS FOR ENGINEERS AND SCIENTISTS, ADVANCED S. World Scientific, 2000.

[5] Y. Li, Y.-H. Yu, "A synthesis of numerical methods for modeling wave energy converter-point absorbers," Renew. Sustain. Energy Rev., vol. 16, no. 6, pp. 4352-4364, 2012, doi: 10.1016/j.rser.2011.11.008.

[6] A. Iturrioz, R. Guanche, J. L. Lara, C. Vidal, I. J. Losada, "Validation of OpenFOAM ${ }^{\circledR}$ for Oscillating Water Column three-dimensional modeling," Ocean Eng., vol. 107, pp. 222-236, Oct. 2015, doi: 10.1016/j.oceaneng.2015.07.051.

[7] M. B. Liu, G. R. Liu, Smoothed particle hydrodynamics (SPH): An overview and recent developments, vol. 17, no. 1. 2010

[8] B. Ren, M. He, P. Dong, H. Wen, "Nonlinear simulations of wave-induced motions of a freely floating body using WCSPH method," Appl. Ocean Res., vol. 50, pp. 1-12, 2015, doi: 10.1016/j.apor.2014.12.003.

[9] A. J. C. Crespo et al., "DualSPHysics: Open-source parallel CFD solver based on Smoothed Particle 
Avicenna An-Nizhami dkk /Jurnal Rekayasa Mesin

p-ISSN: 1411-6863, e-ISSN: 2540-7678

Vol.16|No.1|32-38|April|2021

Hydrodynamics (SPH)," Comput. Phys. Commun., vol. 187, pp. 204-216, 2015, doi: 10.1016/j.cpc.2014.10.004.

[10] M. Gomez-Gesteira, B. D. Rogers, A. J. C. Crespo, R. a. Dalrymple, M. Narayanaswamy, J. M. Domínguez, "SPHysics-development of a free-surface fluid solver-Part 1: Theory and formulations," Comput. Geosci., vol. 48, no. January 2016, pp. 289-299, 2012, doi: 10.1016/j.cageo.2012.02.029.

[11] M. Gomez-Gesteira, A. J. C. Crespo, B. D. Rogers, R. A. Dalrymple, J. M. Dominguez, A. Barreiro, "SPHysics development of a free-surface fluid solver - Part 2: Efficiency and test cases," Comput. Geosci., vol. 48, pp. 300307, 2012, doi: 10.1016/j.cageo.2012.02.028.

[12] A. Colagrossi, M. Antuono, D. Le Touze, "Theoretical considerations on the free-surface role in the smoothedparticle-hydrodynamics model," Phys. Rev. E - Stat. Nonlinear, Soft Matter Phys., vol. 79, no. 5, pp. 1-13, 2009, doi: 10.1103/PhysRevE.79.056701.

[13] J. J. Monaghan, "Simulating free surface flows with SPH," Journal of Computational Physics, vol. 110, no. 2. pp. 399-406, 1994, doi: 10.1006/jcph.1994.1034.

[14] D. Molteni, A. Colagrossi, "A simple procedure to improve the pressure evaluation in hydrodynamic context using the SPH," Comput. Phys. Commun., vol. 180, no. 6, pp. 861-872, 2009, doi: 10.1016/j.cpc.2008.12.004.

[15] G. Fourtakas, J. M. Dominguez, R. Vacondio, B. D. Rogers, "Local uniform stencil (LUST) boundary condition for arbitrary 3-D boundaries in parallel smoothed particle hydrodynamics (SPH) models," Comput. Fluids, vol. 190, pp. 346-361, 2019, doi: 10.1016/j.compfluid.2019.06.009.

[16] B. Leimkuhler, C. Matthews, Molecular Dynamics Interdisciplinary Applied Mathematics. Springer International, 2016.

[17] B. Ren, M. He, P. Dong, H. Wen, "Nonlinear simulations of wave-induced motions of a freely floating body using WCSPH method," Appl. Ocean Res., vol. 50, pp. 1-12, 2015, doi: 10.1016/j.apor.2014.12.003.

[18] B. M. Sumer, J. Fredsøe, Hydrodynamics around cylindrical structures, vol. 12. 2006. 